\title{
REVISITANDO OS PRESSUPOSTOS DA JURISTOCRACIA À \\ BRASILEIRA: MOBILIZAÇÃO JUDICIAL NA ASSEMBLEIA \\ CONSTITUINTE E O FORTALECIMENTO DO SUPREMO TRIBUNAL \\ FEDERAL
}

\section{REVISITING THE CAUSES OF BRAZILIAN JURISTOCRACY: JUDICIAL MOBILIZATION ON THE NATIONAL CONSTITUENT ASSEMBLY (1987- 1988) AND THE STRENGTHENING OF THE BRAZILIAN'S SUPREME FEDERAL COURT}

\author{
Flávia Danielle Santiago Lima \\ Universidade Federal de Pernambuco - UFPE - (Recife, PE, Brasil) \\ Universidade de Pernambuco - UPE - (Recife, PE, Brasil) \\ Universidade Católica de Pernambuco - Unicap - (Recife, PE, Brasil)
}

Recebimento: 29 abr. 2018

Aceitação: 5 jun. 2018

\begin{abstract}
Como citar este artigo / How to cite this article (informe a data atual de acesso / inform the current date of access):
LIMA, Flávia Danielle Santiago. Revisitando os pressupostos da juristocracia à brasileira: mobilização judicial na Assembleia Constituinte e o fortalecimento do Supremo Tribunal Federal. Revista da Faculdade de Direito UFPR, Curitiba, PR, Brasil, v. 63, n. 2, p. 145-167, ago. 2018. ISSN 2236-7284. Disponível em: <https://revistas.ufpr.br/direito/article/view/59168>. Acesso $\quad$ em: $30 \quad$ ago. $2018 . \quad$ DOI:
\end{abstract} http://dx.doi.org/10.5380/rfdufpr.v63i2.59168.

\section{RESUMO}

O trabalho volta-se aos pressupostos da judicialização da política no Brasil, ao questionar os fatores, na Assembleia Nacional Constituinte (1987-1988), que permitiram a expansão do papel institucional do Supremo Tribunal Federal (STF) na futura ordem constitucional. A partir do método dedutivo, parte-se da contribuição de Ran Hirschl (2004), que explica o fortalecimento das cortes, num movimento mundial de relevância dos tribunais, diante das dinâmicas entre os grupos de poder, em sua confiança de que a "juristocracia” lhes seria mais favorável no futuro (autopreservação hegemônica). $\mathrm{O}$ autor destaca o papel dos membros das elites jurídicas e judiciais, como parte relevante nesses processos, em sua pretensão de incrementar seu poder e/ou obter reputação internacional. O estudo de caso brasileiro é amparado na revisão de literatura sobre a transição democrática e o processo constituinte, além de pesquisa documental, para identificar a participação, influências e dissensos entre juristas e ministros do STF durante a assembleia, especialmente na Subcomissão do Poder Judiciário e do Ministério Público.

\section{PALAVRAS-CHAVE}

Juristocracia brasileira. Transição à democracia. Assembleia Nacional Constituinte. Supremo Tribunal Federal. 


\begin{abstract}
The work turns to the causes of the judicialization of politics in Brazil, when questioning the factors, in the National Constituent Assembly (1987-1988), that allowed the expansion of the institutional role of the Federal Supreme Court (STF) in the future constitutional order. From the deductive method, it is based on the contribution of Ran Hirschl (2004), which explains the worldwide movement that strengths judicial institutions, as product of the political dynamics among the internal power groups, in their confidence that "juristocracy" would be more favorable to them in the future (self-interest hegemonic preservation). In this universe, the author highlights the role of members of legal and judicial elites, as a relevant part in these processes, in their claim to increase their power and/or gain international reputation. The Brazilian case study is supported by the literature review on the democratic transition and the constituent process, as well as documentary research, to identify the participation, influences and dissent between jurists and STF justices during the assembly, especially in the Subcommittee on Judiciary and Public Prosecutor's Office.
\end{abstract}

\title{
KEYWORDS
}

Brazilian juristocracy. Transition to democracy. National Constituent Assembly. Supremo Tribunal Federal.

\section{INTRODUÇÃO}

A importância do Supremo Tribunal Federal (STF) no sistema político brasileiro é um fato consolidado. $\mathrm{O}$ encaminhamento de importantes demandas públicas a este órgão jurisdicional, seus procedimentos e ritos e, finalmente, as decisões prolatadas, formam um contexto geral de aprofundamento da relevância de seus membros no jogo político.

Tem-se a versão nacional de um processo de transferência de poder político aos tribunais, com intermediação das instituições jurídicas, estudado sob o conceito acadêmico de judicialização da política, que se presta a explicitar as condições institucionais e comportamentais que redundam no fortalecimento do Poder Judiciário.

Mas quais são as causas da judicialização da política no Brasil?

O fenômeno é creditado ao arranjo institucional previsto na Constituição Federal de 1988 (CRFB), que intentou redefinir as “formas de decidir da política nacional” e, entre outras medidas, fortaleceu o Judiciário, em contraponto ao Poder Executivo (CARVALHO, 2010, p. 177, 186). Por sua vez, os dispositivos constitucionais materiais oferecem a possibilidade da "tradução das demandas políticas na linguagem jurídica, tornando-as “judicializáveis” (LIMA, 2014, p. 221).

Quando comparado ao papel anteriormente desempenhado pelos atores jurídicos, sobretudo seu enfraquecimento nos períodos ditatoriais, o empoderamento é notável. Teria ocorrido, no Brasil, uma inversão de rota nos ambientes altamente judicializados, pois, em vez de “conquistar seu poder, os tribunais receberam uma abundância de poderes na Constituição e somente depois tiveram que decidir como melhor os utilizar sem provocar reações dos poderes eleitos” (TAYLOR, 2007, p. 244). 
Neste contexto, destaca-se a denominada "supremocracia”, que representa a preponderância do STF ante os demais ramos de governo, em que tudo parece exigir uma "última palavra” da instituição, mas também uma concentração de poderes decisórios diante dos demais juízes e tribunais (VIEIRA, 2008, p. 444-445).

Sem prejuízo das críticas suscitadas por este arranjo, o artigo volta-se aos pressupostos da juristocracia, pois se propõe a compreender os fatores que permitiram a expansão do papel do STF na CRFB, a partir dos debates constituintes.

A pesquisa parte do método dedutivo, tomando como premissa a sugestão de Ran Hirschl (2004), que oferece uma interpretação acerca do protagonismo dos tribunais, a tese do "self-interest hegemonic preservation”, sob a qual a participação dos grupos de poder, incluídas as elites jurídicas, com o objetivo específico de ampliar poder na ordem futura, é elemento relevante para a consolidação da democracia judicial - ou juristocracia.

Deste modo, sustenta-se a hipótese de que os juristas, em especial os juízes, não foram apenas destinatários, mas também construtores ativos deste arranjo, ao defender um modelo de exercício da jurisdição constitucional que incrementou o então incipiente controle concentrado, consolidando o papel de "guardião da constituição" do STF.

A pesquisa é bibliográfica, com amparo na revisão de literatura quanto ao tema. Documentos também servirão como base da investigação, sobretudo os referentes aos trâmites da Assembleia Nacional Constituinte (ANC) de 1987, em sua Subcomissão do Poder Judiciário e do Ministério Público, de modo a visualizar a participação e influência de um grupo específico - os juristas em geral e os ministros do STF - nos trabalhos constituintes.

\section{O SUPREMO TRIBUNAL FEDERAL PRÉ-1988: UMA INSTITUIÇÃO SUSCETÍVEL ÀS MUDANÇAS POLÍTICAS}

Ao longo da conturbada história constitucional brasileira, é possível identificar um tortuoso processo de reforço da magistratura, caracterizado por tensões nas relações entre Judiciário e sistema político (KOERNER, 1998). Como expõem Vianna, Burgos e Salles (2007), os juristas sempre tiveram sua relevância no arranjo institucional pátrio, na verificação de uma tendência de instrumentalização dos conflitos sociais e políticos aos entes da justiça, característica do processo de modernização e industrialização nacionais, desde os anos $1930^{1}$.

\footnotetext{
${ }^{1}$ Desse modo, tem-se o fortalecimento do Direito do Trabalho e, consequentemente, a criação da Justiça do Trabalho. Identificou-se, também, o papel da Justiça Eleitoral na apreciação dos conflitos políticos. Por fim, Vianna, Burgos e Salles
} 
O STF foi criado no início da República, com a edição do Decreto nº 510 de 22 de junho de 1890, que também estabeleceu o fim do Poder Moderador. Mas foi a Constituição de 1891, ao aderir aos pilares da democracia norte-americana (separação de poderes, federação e revisão judicial de legislação), que estabeleceu a prerrogativa judicial de anulação das decisões dos Poderes majoritários. Apesar de sua relevância como “árbitros dos conflitos políticos”, os juízes estavam devidamente circunscritos pela função que lhes cabia na distribuição entre os Poderes, por expressos mecanismos normativos de restrição.

A Carta de 1934 estabeleceu a representação interventiva, que atribuía ao Procurador-Geral da República a possibilidade de provocar o STF para apreciação da conformidade dos atos estaduais em desobediência aos princípios federativos, mas cuidou de estabelecer regra que excluía da apreciação judicial questões “exclusivamente políticas” (BRASIL, 1934). Na mesma norma foi instituída a cláusula de reserva de plenário, com a exigência de maioria absoluta para a declaração de inconstitucionalidade, o que também limitava o poder dos tribunais (CARVALHO, 2010, p. 178-183).

O advento do Estado Novo, em 1937, também repercutiu na autonomia do STF, com a aposentadoria do Ministro Hermenegildo Rodrigues, que se mostrava contrário ao regime, por decisão do Presidente Getúlio Vargas. No plano institucional, a edição do Decreto-Lei n. 2.770/40 atribuiu ao presidente da República a competência de nomear, por tempo indeterminado, presidente e vice-presidente dentre os ministros da corte (VIEIRA, 2002, p. 121). Importa destacar que a Constituição de 1937, além de manter a vedação da sindicabilidade judicial dos atos interna corporis de outros Poderes (art. 94), estabeleceu a possibilidade de que, declarada a inconstitucionalidade de uma lei, esta fosse novamente submetida ao Parlamento, para eventual reversão da decisão tornando-a sem efeito - pelo voto de dois terços dos membros de cada Casa (art. 96, parágrafo único) (BRASIL, 1937).

A Constituição de 1946 retirou do ordenamento jurídico essa hipótese de controle político, restabelecendo as inovações da Constituição de 1934 e ampliando o cabimento do recurso extraordinário, para incluir a interposição contra decisões de última instância de todos os juízes e tribunais (art. 101).

Já no contexto de instauração da ditadura militar, teve-se na alteração da composição do STF um instrumento para amoldá-lo às preferências do regime. Posteriormente, foram tomadas medidas para concentração de atribuições no Tribunal, em relação ao próprio Judiciário, mas também estabelecidos mecanismos de interferência em outros Poderes.

(2007, p. 42) apontam a “tradição de conceber a dimensão do público pelo Direito Administrativo”, o que já ocorreria com as relações de classe, por meio do Ministério do Trabalho. 
É interessante perceber que, na vigência da Carta de 1946, sobretudo após a instauração de um regime de exceção, o "diagnóstico do descompasso entre o número de processos ajuizados no STF e a capacidade de julgá-los (BRASIL, 1965, p. 803)” "motivou reformas tanto constitucionais como legislativas” (COSTA; CARVALHO, 2016, p. 167).

Com base do discurso de descompasso entre o número de processos ajuizados e a capacidade de julgamento do Tribunal, a própria Comissão que deu ensejo à PEC 16/1965 cogitou, dentre suas medidas:

\begin{abstract}
causa de prejudicialidade dos recursos para o STF, que somente poderiam ser conhecidos quando dotados de "alta relevância na questão federal suscitada" (BRASIL, 1965, p. 802). Essa proposta, assemelhada ao atual sistema da repercussão geral, foi rejeitada sob os argumentos de que a eminência da Corte Suprema não se deve "ao exercício discricionário e às vezes discriminatório dos seus imensos poderes” e de que causaria a insegurança dos jurisdicionados diante da percepção de que o desfecho dos casos não estivesse diretamente relacionado à lei, mas dependesse de "critérios subjetivos, embora respeitáveis, mas sempre incertos e contingentes, na admissão do último apelo” (BRASIL, 1965, p. 802) (COSTA; CARVALHO, 2016, p. 164).
\end{abstract}

Esse debate foi importante quando da promulgação da EC n. 16/1965, que terminou por estabelecer na Carta de 1946 os primórdios do controle abstrato, a cargo do STF - entre outras medidas de controle do Poder Judiciário por parte deste (remoção e disponibilidade dos juízes, por exemplo) (VIEIRA, 2002, p. 123). Nesse sentido, foi incluída a previsão de cabimento de representação contra a inconstitucionalidade de lei ou ato normativo federal e estadual, no art. 101, “k”, da CF/1946, de competência originária do Tribunal, a ser encaminhada pelo Procurador-Geral da República. Autorizada, ainda, aos estados a regulamentação do procedimento de controle de constitucionalidade, a ser exercido pelo Tribunal de Justiça, quando uma lei municipal afrontasse a constituição estadual (art. 124, XIII da CF/1946).

A promulgação da referida emenda teve por objetivo conformar o Judiciário às pretensões do regime, considerando que o Procurador-Geral da República era então indicado pelo Presidente da República; aliado, portanto, do Chefe do Executivo (VIEIRA, 2002, p. 123). Tal objetivo foi logrado com a edição dos Atos Institucionais n. 5 e 6, com a redução da quantidade de ministros para onze eram 16 dezesseis - e a aposentadoria compulsória daqueles contrários ao regime (CRUZ, 2004).

Além dos instrumentos institucionais estratégicos, relata-se o apoio dos ministros do Tribunal ao regime, seja pela presença do então Presidente Ribeiro da Costa, na sessão extraordinária que antecedeu a edição do Ato Institucional n. 1, mas também pela ausência de reação pública por parte dos ministros. Em outras palavras, “o STF não praticava o antigoverno”, como diria anos posteriormente o Ministro cassado Hermes Lima (apud RECONDO, 2018, p. 35 et seq.). 
Com o STF controlado, foi instituída a representação interventiva pela EC n. 01/1969, e posteriormente, por meio da EC n. 07/1977, foi dada ao STF a competência para interpretar ato normativo, com efeito vinculante, e foram instituídas a avocatória e a arguição de questão federal relevante (ANDRADE, 2015, p. 45-46).

A combinação da avocatória com a arguição de questão federal relevante (arguição de relevância) resultou em significativo aumento de poder do Tribunal, uma vez que por meio da avocatória o Procurador-Geral da República poderia requerer que o Tribunal avocasse a competência de análise de qualquer processo, desde que envolvesse perigo grave e imediato de lesão à ordem, à segurança, à saúde e à economia pública, podendo, inclusive, suspender os efeitos de decisão eventualmente proferida para devolver à Corte o conhecimento integral do processo (BRASIL, 1977).

Conforme a arguição de relevância, o Supremo poderia apreciar um processo que não era de sua competência inicial; para isso, no próprio recurso extraordinário deveria ser feita uma preliminar demonstrando a relevância e requerendo a formação do instrumento. A apreciação da arguição seria realizada por um conselho designado pelo Presidente do Tribunal, sua decisão seria irrecorrível e não precisaria conter fundamentação, tal como o writ of certiorari norte-americano.

Ainda a partir da Emenda Constitucional (EC) 16/1965, foi incrementada a função de controle do aparato judicial, uma vez que o Tribunal passou a ser responsável por decidir procedimentos de remoção e disponibilidade dos juízes, por exemplo.

A promulgação da referida emenda expõe o objetivo de conformação das pretensões do regime, considerando que o Procurador-Geral da República era então indicado pelo Presidente da República; aliado, portanto, do Chefe do Executivo (VIEIRA, 2002, p. 123).

Deste modo, em paralelo ao incremento das atribuições e concentração de funções no STF, “as interferências no Judiciário e nos pressupostos de sua independência constitucional foram constantes, e tanto mais graves quanto mais precária era sua identidade institucional e mais débeis as garantias da magistratura”. Ou seja: num país de tradição autoritária, tem-se que “em todos os momentos em que se quebrou a ordem democrática, Judiciário foi sensivelmente abalado”, como descreve Maria Tereza Sadek (1995, p. 14).

Mas por que o Judiciário fortaleceu-se com a redemocratização? 


\section{A JURISTOCRACIA COMO PRODUTO DA AUTOPRESERVAÇÃO DAS ELITES HEGEMÔNICAS (E JURÍDICAS)}

O fortalecimento das cortes, a partir de constituições que transferem para estas instâncias os grandes conflitos sociais e políticos, tem diversas explicações.

O projeto constitucionalista tem relevância particular nos momentos de reestruturação institucional, talvez porque, como comenta Boaventura de Sousa Santos (2001, p. 125-177), “a ambiguidade da intervenção dos tribunais [...] revela-se particularmente útil sempre que as forças políticas não conseguem chegar a um compromisso político em questões estruturantes”.

A tese da fragmentação política enfatiza, nas transições à democracia, a necessidade de instituições protetoras de um espectro de valores contra os abusos políticos. Este potencial ganhou relevo na Europa após a Segunda Guerra Mundial, a partir da ampliação do catálogo de direitos, da desconfiança dos parlamentos (inaptos para frear o avanço dos regimes totalitários) e da criação dos tribunais constitucionais como instituições apartadas da estrutura judicial. Na Itália e na Alemanha, a possibilidade de indicação de membros pelos diversos partidos e o afastamento das cortes da magistratura ordinária teriam contribuído para a aceitação deste novo arranjo. Nos EUA, esse potencial foi anunciado no rodapé do caso Carolene Products, que marcou a nova posição da Suprema Corte, especialmente após as nomeações de Roosevelt, e constituiu fundamento para o célebre julgado de Brown v. Board of Education² (FEREJOHN, 2002, p. 57-58).

É interessante observar que as referidas hipóteses referem-se, sobretudo, aos contextos europeu e norte-americano, não abrangendo as ondas de constitucionalização mais recentes (América Latina, África, Ásia e democracias consolidadas, como a canadense). Partindo dessa constatação, há uma tendência de aplicar novas teorias explicativas sobre os processos de adoção e aprofundamento da judicialização em sociedades multifacetadas. Neste sentido, Ran Hirschl oferece um inventário das teorias que justificariam estes processos e, posteriormente, lança sua hipótese.

Para o autor, as teorias classificadas de "evolucionistas” asseveram a inevitabilidade do progresso judicial e creditam o fenômeno aos "macrofatores endógenos", como a necessidade de autocomprometimento dos atores políticos, devido à pouca confiança nos instrumentos tecnocráticos de poder.

As “explicações funcionalistas” justificariam a constitucionalização diante das necessidades sociais, eis que seus instrumentos seriam aptos a assentar a continuidade dos processos públicos e a

\footnotetext{
${ }^{2}$ Segundo o autor, a experiência negativa com os parlamentos nas décadas de 20 e 30 superou o preconceito das esquerdas, que viam a revisão judicial como um instrumento contramajoritário e, com amparo na experiência norte-americana de então, voltado à garantia da propriedade privada (FEREJOHN, 2002, p. 56-7).
} 
unidade política. Elas enfatizam que as transformações jurídicas podem melhorar a eficiência das deliberações políticas, ao definir que os opositores monitorem os políticos e demais grupos políticos. A expansão das agências administrativas semiautônomas e reguladoras exige um Judiciário ativo, a afiançar as condições da política. Nas organizações supranacionais, um órgão judicial comum, como possui a União Europeia, permite a coordenação dos ordenamentos, com a adoção dos vetores comuns na legislação interna de cada integrante. A deferência ao sistema jurídico, portanto, consistiria numa resposta orgânica às pressões do próprio sistema político.

Os “modelos institucionais econômicos" sustentam a constitucionalização em virtude da garantia de previsibilidade da regulação governamental do mercado, pois a jurisdição converte-se num mecanismo "apolítico" de controle da atividade burocrática. Afasta-se a dependência dos investimentos econômicos do setor político, que não mais condicionariam o mercado. Os parâmetros de intervenção estatal na atividade econômica são afirmados pela legislação, que delineia a esfera de discricionariedade dos juízes no julgamento dessas ações.

Traçadas as linhas gerais de cada hipótese, o autor atenta para suas insuficiências e inconsistências. Os vetores políticos específicos de cada processo de judicialização careceriam de análise mais apurada, para destacar em que condições políticas surgem e, posteriormente, comparar as constatações de forma sistêmica. Essas teorias negligenciariam, ainda, as repercussões dos comportamentos individuais e dos interesses que os mobilizam, especialmente dos fatores que provocam a aceitação dos agentes que, a rigor, são prejudicados pelas limitações ínsitas a qualquer processo de constitucionalização.

Desse modo, a transferência de poder ao Judiciário não é fruto de um processo isolado, mas um acordo entre diversas forças, que possivelmente deve ir ao encontro do interesse desses atores, que assumem os riscos desse processo porque acreditam que sua posição será melhorada numa “juristocracia” (HIRSCHL, 2004, p. 37).

No esclarecimento de sua tese da "self-interest hegemonic preservation", cogita que os demais agentes políticos são movidos pelo intento de aumentar ou manter seu poder, determinar os rumos da política geral, mas sob um discurso democrático. Os agentes econômicos, por sua vez, pretendem assegurar liberdades econômicas, em vista do reconhecimento dos direitos fundamentais. Certamente, tais interesses devem encontrar ressonância nas elites judiciais, que se animariam diante da possibilidade de aumentar sua influência política e, ainda, conquistar reputação internacional.

Mais que considerações altruísticas ou morais que favorecem tal fortalecimento, são esses interesses específicos, baseados na crença de que a atividade das cortes os espelhará, que explicam a 
constitucionalização dos sistemas políticos. Juntamente com os fatores internos, atualmente é enfatizada, de igual modo, a relevância dos condicionamentos externos.

Portanto, a judicialização condiciona a política, mas também é um instrumento desta, pois está respaldada na convergência de interesses dos diversos grupos preponderantes numa sociedade. O estabelecimento das condições destas interações, contudo, depende da análise de cada contexto, na busca do entendimento de suas origens e de suas consequências.

No caso brasileiro, verificar-se-á que o processo político que culminou com a adoção da Constituição de 1988 foi um momento peculiar da nossa história, marcado pela consciência da necessidade de formatação de um novo arranjo institucional. Seguindo a tendência mundial, as forças políticas preponderantes na década de 80 viram no direito e demais organismos estatais um mecanismo para a manutenção do acordo por elas firmado.

\section{A ASSEMBLEIA NACIONAL CONSTITUINTE DE 1987 E 0 DESAFIO DEMOCRÁTICO: OS DISSENSOS}

Diante do contexto da ditadura militar, a Constituinte de 1987-1988 adquiriu um papel determinante e singular na tentativa de coadunar os interesses envolvidos no processo de transição do regime ditatorial para o regime democrático.

As explicações sobre a transição democrática dependem, num primeiro momento, da eleição de um enfoque analítico. Como observa Carlos Arturi (2001, p. 13), nas primeiras “ondas” de transição era privilegiada a influência das variáveis econômicas (grau de desenvolvimento), sociais (modernização) e culturais (cultura cívica) nos processos de mudança (explicações macroorientadas). Já as transições da terceira onda de democratizações, sobretudo na América Latina, expuseram a necessidade de novas leituras, que privilegiassem também as variáveis referentes à intervenção e ao voluntarismo dos atores políticos envolvidos nestas dinâmicas (enfoque “micropolítico”).

No caso brasileiro, o final do período autoritário evidenciou as tensões entre os atores envolvidos no processo, caracterizado por constantes crises. A ausência de regras claras e os constantes embates para a sucessão dos chefes militares são significativos das oscilações nas relações entre os grupos. Tido como um dos mais longevos da América Latina, o regime militar brasileiro pode ser isolado em cinco grandes fases: constituição (Castello Branco e Costa e Silva, 1964-1968); consolidação (Médici, 1969-1974); transformação (Geisel, 1974-1979); desagregação (Figueiredo, 
1979-1985) e, por fim, a transição para um regime liberal-democrático no governo de José Sarney (1985-1989).

Em seu ocaso, deu-se a previsão de Ernesto Geisel, de uma “distensão política, lenta, gradual e segura”; posteriormente conhecida como "política de abertura” e, ainda, “transição política”, contexto em que se insere a ANC de 1987-1988 (ARTURI, 2001, p. 13).

Há controvérsia quanto aos agentes propulsores do processo de mudança. Esta teria sido iniciada pelos próprios militares para resolver questões internas da corporação - com suas diversas orientações político-ideológicas - que puderam determinar sua natureza, andamento e objetivos. A sociedade civil teria influenciado, sobretudo, o ritmo dos acontecimentos (CODATO, 2005, p. 83).

Não por acaso, para Adam Przeworski (1992), toda transição à democracia seria "conservadora”, ao assegurar aos antigos dirigentes autoritários a garantia da propriedade privada, proteção contra eventuais perseguições e, ainda, sobrevivência política na nova ordem. E, no futuro, esses elementos podem se constituir em obstáculos à democracia. Nesse sentido, “a interação entre a estrutura econômica, social e política pré-existente e a estratégia dos atores políticos permite arranjos institucionais e comportamentais que condicionam as possibilidades de uma consolidação democrática” (ARTURI, 2001, p. 15).

Aqui não houve uma ruptura institucional, mas foram privilegiados os acordos que favoreceram um processo lento e gradual, que encontrou resistência nas classes médias urbanas, como exemplificado no movimento de Diretas Já. Optou-se por manter a governabilidade e as rotinas do processo decisório, numa transição negociada, caracterizada "pela capacidade dos dirigentes do regime e os militares de limitarem o andamento e o alcance da redemocratização”, mas também por sua permanência nas "instâncias decisórias cruciais do Estado e pela renovação da aliança entre aqueles, políticos conservadores e empresariado ao longo do processo” (KOERNER; FREITAS, 2013, p. 181).

De toda sorte, neste processo de transição entre o regime ditatorial e a redemocratização, tinha-se como exigência a elaboração de uma nova constituição, uma vez que, por quase toda a década de 80, a convivência de um processo gradativo de redemocratização ocorreu de forma simultânea à vigência do Ato Institucional n. 5, que respaldou juridicamente a ditadura militar. Assim, diante da "reiterada constitucionalização das normas antidemocráticas e das medidas de exceção por parte dos militares e dos seus aliados civis, conjugada ao déficit de legitimidade da ordem autoritária”, era necessário assegurar uma “institucionalidade democrática” (ROCHA, 2013, p. 29).

Como todo acordo, convivia-se, ao lado da comunhão acerca de determinados princípios, com a carência de “elementos de consenso sobre as políticas concretas e as soluções a serem 
implementadas pelo novo governo, tampouco quanto à direção que se dará ao processo de mudança” (ABRANCHES, 1988, p. 8). Por isso, a redemocratização institucional implicou descontinuidades e desajustes entre as forças que a orientaram.

A constituinte era defendida por quadros relevantes da oposição ao regime militar e da mobilização popular, como Ulysses Guimarães:

Um povo só se autodetermina politicamente pela democracia [...]. O caminho histórico e universal indicado pela honestidade política e trilhado pelos democratas sinceros e coerentes é a convocação de uma Assembleia Nacional Constituinte, proposta urgente, institucional e salvadora do MDB. (apud DELGADO, 2006, p. 188).

Em meados de 1985, havia uma grande dúvida acerca do formato da futura assembleia: autônoma (exclusiva) ou congressual, mediante a atribuição de poderes constituintes ao Congresso Nacional eleito. Esta primeira discussão antecipou o debate entre as forças políticas que caracterizou todo o período constituinte.

Nesse sentido, observa-se a preferência, na análise dos grupos políticos durante a transição brasileira, pela distinção entre progressistas e conservadores, a partir da organização de preferências e princípios semelhantes (PILATTI, 2008).

De acordo com a trajetória narrada por Sandra Gomes (2006, p. 202), o primeiro grupo teve origem no partido de oposição ao regime militar, o MDB (Movimento Democrático Brasileiro), com o reforço de dissidentes do partido governista, numa aliança estratégica no momento da eleição indireta para a Presidência da República, no Colégio Eleitoral em 1985. Já os conservadores, após o enfraquecimento do PDS (Partido Democrático Social) nas citadas eleições, difundiram-se por diversas agremiações, inclusive no próprio PMDB, surgido em 1980 a partir do MDB.

No que se refere à assembleia, os progressistas compreendiam o legislativo como "uma instituição estruturalmente vocacionada para o conservadorismo, potencialmente controlada pelos grupos oligárquicos tradicionais da política brasileira” e defendiam uma “Constituinte Exclusiva”, distante das regras eleitorais estabelecidas para a representação ordinária (PILATTI, 2008, p. 21).

Já o consórcio conservador, formado pela maioria liberal no Congresso em 1985, Presidência da República e pressões dos militares, inclinava-se por um modelo consensual, de modo que a Assembleia seria formada pelos membros da Câmara dos Deputados e do Senado que seriam eleitos em 1986, com a participação dos 23 senadores biônicos (não eleitos pelo voto popular direto), designados pelo regime militar no início dos anos 80 (ARTURI, 2001, p. 23).

Ao final, a Emenda Constitucional n. 26, de 27 de novembro de 1985, convocou uma Assembleia Constituinte, de nítido caráter congressual. E, no pleito de 1986, foram eleitos 217 
deputados que compunham a sigla partidária de apoio ao antigo regime (ARENA) e 212 do partido de oposição (PMDB) (ARTURI, 2001, p. 23).

Além da cisão política, a singularidade desse processo decisório deu-se justamente porque a Constituinte foi composta por membros do Congresso Nacional, envolvidos tanto na produção legislativa ordinária como na extraordinária. Os parlamentares incumbidos da missão de elaborar o novo texto constitucional, sendo eles representantes eleitos de interesses diversos, não conseguiriam distanciar-se de fatores políticos e eleitorais no contexto de suas propostas ou decisões no processo constituinte. Para Marcia Souza (2003, p. 38), as constituintes “espelham momentos de tensão e conflitos, uma vez que são instaladas para instituir um novo ordenamento do poder, ao mesmo tempo em que, simbólica e efetivamente, devem alterar ou eliminar a moldura política antecedente”.

Assim, os trabalhos da ANC foram iniciados sem previsão dos seus rumos, pois não havia um grupo hegemônico que reunisse condições de impor seu projeto ao País. Apesar da tensão característica desse momento histórico de transição democrática, havia consenso em torno da garantia de direitos fundamentais, da organização política e do fortalecimento das instituições judiciais. Esses consensos, entre outros, derivavam da necessidade de superação do regime político anterior e do compromisso dos constituintes de atenderem esses anseios. Existia, assim, a responsabilidade de criar as condições jurídicas para a estabilização das instituições governamentais, de sorte que as demandas, nos termos da democracia representativa, fossem processadas pelos meios institucionais, tanto legislativos quanto judiciais. Abria-se aos constituintes o desafio de assegurar instrumentos normativos para a promoção de mudanças socioeconômicas, aptas a garantir a legitimidade do sistema político e jurídico.

Entretanto, é notório que os conflitos de interesses geraram importantes e intensos debates entre os atores políticos, em que a participação da sociedade civil se manifestou como reflexo da diversidade de anseios que aquele momento histórico abrigava ${ }^{3}$. Em verdade, não havia um grupo hegemônico que reunisse condições de impor seu “projeto” ao País. Mas os setores então organizados participaram ativamente do processo, em que predominaram os acordos e complexas negociações:

Nas Assembleias Constituintes convivem a linguagem da negociação e da argumentação, como duas formas de comunicação que ora se justapõem ora prevalecem uma sobre a outra, dependendo das contingências específicas. No caso brasileiro em tela, os recursos comunicativos acima assinalados foram potencializados pela intensa presença de inúmeros grupos e segmentos organizados da sociedade que estabeleceram contato com os constituintes durante os trabalhos constitucionais (SOUZA, 2003, p. 41).

\footnotetext{
${ }^{3}$ Ali aconteceu um "processo decisório caracterizado pelo dissenso, pela intensa e permanente mobilização de atores coletivos internos e externos, por votações altamente polarizadas e, ao mesmo tempo - sobretudo em sua fase final -, por uma atividade igualmente intensa e incessante de busca de acordos entre as lideranças das diferentes forças em choque.” (PILATTI, 2008, p. 1).
} 
A despeito da forte influência dos diversos atores sociais no processo constituinte, na exigência da previsão e proteção constitucional de suas demandas, as manobras das elites podem ser percebidas neste processo decisório, em que se buscou a preservação de privilégios e preponderância dos grupos de interesses historicamente consolidados.

\section{OS TRABALHOS NA SUBCOMISSÃO TEMÁTICA DO PODER JUDICIÁRIO E DO MINISTÉRIO PÚBLICO: OS JURISTAS NA CONSTITUINTE}

Os trabalhos da ANC foram iniciados em $1^{\circ}$ de fevereiro de 1987 e concluídos em cinco de outubro de 1988, data da promulgação da Constituição de 1988. Participaram da formulação da nova carta 72 Senadores (23 eleitos em 1982 e 49 em 1986) e 487 Deputados.

Optou-se por um modelo fortemente descentralizado, com a distribuição das atividades entre oito Comissões Temáticas, com 63 membros cada. Essas comissões, por sua vez, dividiam-se em três Subcomissões, de sorte que foram organizadas 24 Subcomissões.

De acordo com o Regimento Interno (BRASIL, 1987, art. 14), as deliberações das subcomissões partiam de sugestões encaminhadas por constituintes e sociedade civil, em reuniões e audiências públicas. Cabia ao relator, nesse contexto, coletar as propostas, dar um parecer e submetêlas à votação no âmbito da subcomissão. Após a aprovação por maioria simples, tinha-se um anteprojeto que era encaminhado para a respectiva Comissão Temática, que votava e enviava o relatório para a Comissão de Sistematização, encarregada de propor um Anteprojeto de Constituição ao plenário da Assembleia Nacional Constituinte, para discussão.

Os critérios para a estruturação das atividades chamam a atenção pelo alto grau de participação popular e de independência no âmbito das subcomissões, na preferência por um processo deliberativo "elaborado de baixo para cima” (GOMES, 2006, p. 196), com a abertura de um "canal de diálogo entre sociedade e estado, viabilizando a participação de qualquer cidadão na formulação do texto Constitucional” (LOUBACK, 2016, p. 100).

A apresentação de emendas populares foi um importante instrumento, chegando-se a 12 milhões de assinaturas coletadas e 122 emendas "apresentadas no anteprojeto da constituição”, de sorte que expressivo contingente da população brasileira envolveu-se na construção do texto ${ }^{4}$. Foram

\footnotetext{
4 “De acordo com Nelson Lin (2010), dentre os requisitos para se apresentar uma proposta de emenda popular era fundamental [...] "a participação de, no mínimo, três entidades da sociedade civil e a existência de, no mínimo, 30.000 assinaturas, sendo que cada cidadão poderia assinar três emendas populares” (LIN, 2010: 54). [...] Assim, conclui-se que de 4 a 12 milhões de cidadãos participaram da Constituinte através das emendas populares” (LOUBACK, p. 2016, p. 100).
} 
regulamentadas, ainda, as audiências públicas, num esforço deliberado de integração com os anseios populares.

As palavras do constituinte Octávio Elísio, expostas no Diário da Assembleia Nacional Constituinte, no Suplemento de 16/7/1987, são representativas do momento:

A verdadeira Constituinte acontece fora do prédio do Congresso, e que esta Assembleia Nacional Constituinte, que, aqui e agora, se reúne em Subcomissões, não vai responder aos anseios da sociedade se não ouvir essa sociedade (p. 190 apud BACKES; AZEVEDO; ARAÚJO, 2009, p. 3).

Em contrapartida, referido modelo gerou muitas "rodadas de negociação" (LAMOUNIER, 1990, p. 82). O Anteprojeto e o Primeiro Projeto de Constituição, produzidos em conformidade com o Regimento, receberam fortes críticas pelos mais diversos setores, pois considerados documentos “cheios de decisões incoerentes, grande demais, cheio de particularismos, 'simplesmente terrível' [...], um verdadeiro 'Frankenstein’” (GOMES, 2006, p. 197). Posteriormente, teve-se um esforço de sistematização e a aprovação do Segundo Regimento Interno, cujo formato teve consequências para os rumos da Carta vindoura.

Especificamente, a nova estrutura do Poder Judiciário é oriunda do trabalho da Subcomissão do Poder Judiciário e do Ministério Público (SPJMP), pertencente à Comissão da Organização e Sistema de Governo da Assembleia Nacional, cujas atividades se iniciaram em sete de abril de 1987. Seus membros foram indicados pelas lideranças partidárias, com atenção ao critério de proporcionalidade previsto na Resolução de n. 2 da ANC (BRASIL, 1987). Seu presidente foi o constituinte José Costa. Jairo Carneiro e Plínio Sampaio atuaram como primeiro e segundo vicepresidentes, respectivamente. Plínio Sampaio ainda desempenhou a função de relator. A Subcomissão possuía uma relativa homogeneidade com relação aos seus membros, pois composta em sua grande maioria por advogados. No total, 87,5\% dos seus integrantes possuíam bacharelado em Direito; na ANC, a proporção já era bastante expressiva - 40,14\%.

Politicamente, a Subcomissão possuía ampla maioria progressista, em que "o poder hegemônico do PMDB foi dividido com o poder dos bacharéis”, eis que 11 integrantes pertenciam ao PMDB, um constituinte era do PDT e três, do PFL. O Relator, Plínio Sampaio, era do PT. Neste quadro, interpreta-se que houve "baixa polarização" e os interesses foram setorizados (CARVALHO NETO, 2007, p, 316).

Como esperado, a Subcomissão também foi marcada pela forte participação de juristas de profissão e acadêmicos das diversas áreas do direito. Os relatos mostram a constante presença de desembargadores, juízes, professores, advogados, assim como presidentes de associações de setores 
do Poder Judiciário, além do Ministro da Justiça. Já as audiências públicas foram uma das formas de ouvir a sociedade civil e as entidades ligadas às temáticas em discussão. Ao todo, realizaram-se 10 audiências públicas, com duração de três horas. As personalidades e entidades convidadas para participar das audiências foram escolhidas mediante votação. Apesar do convite a setores da sociedade civil, há de se ressaltar que "questões corporativas efetivamente dominaram uma parte substancial dos debates, e mesmo a escolha dos depoentes enfatizou as profissões ditas jurídicas, presumivelmente em função de uma abordagem mais ‘técnica' e setorial do tema” (TAVARES FILHO, 2009, p. 222).

Os setores corporativos, sempre presentes, articularam-se ao final para rejeitar as propostas de alteração no aparato judicial sugeridas pelo Relator, que consistiam na “extinção dos juízes classistas da Justiça do Trabalho, o fim da Justiça Militar, a criação de um tribunal constitucional, a estatização dos cartórios, a criação de uma Justiça Agrária, entre outros” (CARVALHO, 2005, p. 111).

Desse modo, a participação dos profissionais do Direito garantiu o aspecto técnico e a proteção de seus interesses de classe, com o fortalecimento das instituições judiciais que lhes assegurou protagonismo no cenário político vindouro 5 .

\section{O “NOVO” SUPREMO TRIBUNAL FEDERAL: ESCOLHAS CONSTITUINTES E PARTICIPAÇÃO DO MINISTROS}

Considerando que a Constituição surge como instrumento de reação ao poder ditatorial, ao trazer em seu texto os anseios de mudanças substanciais no campo da política e na previsão e proteção dos direitos fundamentais, o Poder Judiciário passa a ser depositário do papel de garantidor da concretização do processo de redemocratização brasileira.

Trata-se de uma visão já presente nos debates anteriores à ANC, como no anteprojeto elaborado pela Comissão Provisória de Estudos Constitucionais, sob a égide de Afonso Arinos, que teria introduzido os princípios do constitucionalismo comunitário, de nítida influência alemã, no Brasil (PILATTI, 2008, p. 21). A noção de uma constituição dirigente, cuja normatividade deveria ser assegurada por uma jurisdição forte, também se fazia presente entre os constitucionalistas brasileiros. O sucesso destas construções teóricas nos países ibéricos, que haviam superado regimes

\footnotetext{
${ }^{5}$ Em outro momento decisivo para a conformação do sistema de justiça, a Reforma do Poder Judiciário, que culminou com a aprovação da EC 45/2004, a articulação entre STF, lideranças associativas e juristas no Executivo (Ministério da Justiça) e Legislativo também se fez presente, como descreve Frederico de Almeida (2010, p. 281-286).
} 
autoritários e produziram constituições democráticas (Portugal, 1976; Espanha, 1978), expunha as potencialidades da adesão ao projeto constitucional (LIMA, 2009). Nesse sentido,

O Judiciário seria o “timoneiro” a ter nas mãos “uma nau em mar turbulento”, responsável pela transição do regime autoritário para um estado de Direito Democrático. Segundo Marcio Thomaz Bastos, presidente da $\mathrm{OAB}$, os juízes teriam como missão fundamental contribuir a "cada sentença" para "remover o entulho autoritário" que ainda persistisse. (TAVARES FILHO, 2009, p. 219).

Assim, o receio quanto a um retorno autoritário foi respondido pelo fortalecimento das instituições jurídicas, como a Ordem dos Advogados do Brasil (OAB), o Ministério Público e o Judiciário, tidos como "peças essenciais para o bom funcionamento da democracia”, e o estabelecimento de garantias aos seus membros.

Nesse contexto, o Supremo Tribunal Federal - como órgão de cúpula - assegurou proeminência. Na verdade, a instituição influenciou o próprio processo constituinte, desde a condução dos debates até o processo decisório, à medida que seus ministros participaram da definição do próprio formato da Assembleia Nacional Constituinte, eis que a adoção de um modelo congressual por via de emenda constitucional e as dúvidas sobre a aplicação intertemporal das regras discutidas davam um ar de incerteza ao processo. Por isso, o STF foi acionado em diversos momentos críticos para dirimir os conflitos de interesses, tendendo sempre a posicionamentos mais próximos da ala conservadora.

O STF incide sobre o processo de três modos: como recurso estratégico mobilizado pelos agentes para sustentar suas posições nos momentos críticos; como arena decisória que, ao decidir litígios, atua como instância normativa que fixa o significado jurídico dos conflitos políticos e, por fim, como instância legitimadora da atuação dos ministros como opinantes constitucionais (KOERNER; FREITAS, 2013, p. 142).

Necessário destacar que pairava um ar de incerteza sobre a aplicabilidade do texto constitucional, levando juristas e os próprios ministros do STF a adotar posicionamentos diversos. Diante disso, os ministros do STF e de outros tribunais, temendo decisões divergentes, reuniram-se para decidir como aplicariam os dispositivos da Assembleia considerados controversos.

No que se refere à futura configuração institucional, é possível isolar três grandes propostas acerca da estrutura do STF na ordem constitucional vindoura.

\footnotetext{
6 "Esta especificidade brasileira é tão gritante que o próprio texto constitucional atribui aos advogados o caráter essencial à administração da justiça. Entre os seus dispositivos, a Constituição brasileira faz alusão ao termo advogado em 23 momentos distintos. Se comparado a países que passaram por um processo similar de redemocratização no mesmo período histórico, como Argentina (3 alusões) e Chile (14 alusões), este fato é extremamente significante" (CARVALHO; BARBOSA; GOMES NETO, 2014, p. 73).
} 
Tanto na SPJMP como na Subcomissão dos Direitos Políticos, dos Direitos Coletivos e das Garantias, cogitou-se a criação de um tribunal constitucional, cujos membros teriam mandatos temporários de no máximo 12 anos e seriam escolhidos pelo Congresso Nacional ou pelos três Poderes da República.

Na Subcomissão dos Direitos Políticos, o então constituinte Michel Temer (PMDB) defendeu a permanência das funções desempenhadas pelo Tribunal (unificação da legislação federal) e da vitaliciedade de seus membros, com a criação de uma sessão especializada em questões constitucionais, esta composta por ministros com mandatos temporários.

Por fim, a manutenção da estrutura existente, com a permanência das funções de tribunal constitucional, federal e de cassação, composto por ministros vitalícios, era a preferida pelos membros da instituição, como explicitou o Ministro Sydney Sanches em audiência pública. Tinha ainda o apoio da Associação dos Magistrados do Brasil (AMB). E convergiria com os interesses do governo, conforme salientado pelo então Ministro da Justiça (e posteriormente Ministro do STF), Paulo Brossard.

Nas palavras do Relator da Subcomissão, Plínio de Arruda Sampaio, “o grande lobby, a grande dificuldade que eu tive aqui foi o pessoal que estava ligado ao Supremo. O Supremo não queria isso (um Tribunal Constitucional), ele queria essa coisa mista que saiu, que eu acho que foi uma pena, eu fui derrotado nisso” (CARVALHO, 2005, p. 107-108).

Já na Comissão da Organização dos Poderes, foi aprovada a continuidade quanto à estrutura do STF e ampliação dos legitimados ativos para propositura das ações do controle concentrado de constitucionalidade. A abertura do controle é considerada uma importante causa da judicialização da política, ao facilitar o acesso de diversos grupos políticos ao Tribunal, rompendo com o monopólio do Procurador-Geral da República na ordem constitucional anterior, que se convertia numa espécie de antecâmara decisória para o questionamento da legislação no STF (CARVALHO NETO, 2007, p. 322-323). Interessa notar que esta foi uma proposta dos grupos de centro-esquerda, que contou com apoio de emenda popular com 39 mil assinaturas (KOERNER; FREITAS, 2013, p. 167). Embora não tivesse, num primeiro momento, amparo no STF, os ministros não se mobilizaram para sua retirada.

Mais uma vez, o envolvimento dos juristas e os interesses dos ministros ficam claros nas palavras do Relator Plínio de Arruda Sampaio:

Eles estavam preocupados com os artigos 101 e 102, o 103 eles deixaram passar [...] Eu fui ao Supremo conversei muito com eles, mas eles não abriram mão. Através do Maurício Correa fizeram as emendas e mudaram. Com o artigo 103 eles não criaram o menor problema eles estavam interessados era nisso (arts 101 e 102). Uma vez que eles ganharam o que eles queriam eles não fizeram nenhuma força, então isso passou sem muita dificuldade [...] Isso 
na verdade foi fruto dos acadêmicos que me assessoraram com as novas teorias da constitucionalidade, não houve uma pressão popular por isso, nem uma contra-pressão política por isso (CARVALHO, 2005, p. 107-108).

As atenções, portanto, direcionavam-se à polarização da discussão em torno da criação de um tribunal constitucional, presente durante o longo processo de sistematização das propostas e votação. Neste tema, a participação dos ministros do STF foi acentuada, com presença em debates e audiências públicas, negociações com a direção da Constituinte e “ameaças veladas”, como a sugerida pela afirmação de Oscar Corrêa (1987, p. VIII apud KOERNER; FREITAS, 2013, p. 167), de que os ministros eram discretos porque o STF “poderia vir a ter que dirimir” a controvérsia” no que se refere ao próprio trâmite da Assembleia Constituinte.

O intenso lobby foi bem-sucedido, de sorte que nos substitutivos do relator (projetos conhecidos como “Cabral 1” e “Cabral 2”, em referência ao constituinte Bernardo Cabral), o número de ministros foi reduzido de 16 para 11. Neste momento, também foi mantida a competência originária para julgamento das ações em que figuram presidente da República, Câmara dos Deputados e Senado Federal e as altas autoridades dos Poderes, elemento-chave para a compreensão do relevante papel do STF na ordem constitucional ulterior.

Após as primeiras vitórias, percebe-se com mais clareza as distinções entre os grupos progressistas e conservadores no que concerne à centralização de competências e composição do Tribunal. Estes voltaram-se ao combate das propostas de criação do Superior Tribunal de Justiça e do Conselho da Magistratura, de sorte a fortalecer o STF. Aqueles permaneceram engajados na apresentação de emendas tendentes a modificar a configuração aprovada no projeto de sistematização, como a alteração da composição e dos critérios para nomeação, estabelecimento do mandato de oito anos, supressão da competência para apreciar recurso extraordinário e outros ${ }^{7}$. Durante as votações seguintes, as emendas propostas pelos grupos de centro-esquerda foram rejeitadas (KOERNER; FREITAS, 2013, p. 168-174).

Afirma-se que a única derrota dos interesses dos então ministros do STF refere-se à perda da competência de uniformização de jurisprudência quanto à legislação federal, diante da criação do Superior Tribunal de Justiça (CORRÊA, 1987).

Dentro desse contexto, por óbvio, foram expandidas as funções do STF, a partir de uma estrutura que concentra atribuições as mais diversas no Tribunal e de um renovado desenho de revisão

\footnotetext{
${ }^{7}$ A ampla participação de juristas no processo quanto ao tema foi exposta por Plínio Sampaio: “Eu tenho impressão que aqui quem teve força foi José Afonso da Silva, tudo que teve maior abertura na Constituição teve sua influência. [...] O Marrey, que atualmente é secretário da justiça de José Serra, era o meu assessor mais direto para esses assuntos, o Geraldo Ataliba, grande jurista, são as pessoas com as quais eu mais conversei sobre esse capítulo aqui. A idéia era expandir, aumentar, ampliar o uso". (CARVALHO, 2005, p. 106-107).
} 
judicial de legislação que une os controles concreto e abstrato sob sua tutela. Desta conjunção de tarefas, surgiu uma instituição mais forte do que os modelos europeus que inspiraram teoricamente os constituintes (CARVALHO, 2005, p. 88). Como salienta Oscar Vilhena Vieira (2008, p. 444), o STF tornou-se “uma instituição singular em termos comparativos, seja com sua própria história, seja com a história de cortes existentes em outras democracias, mesmo as mais proeminentes”"

A atuação de juízes e ministros do STF, aliados aos setores mais conservadores da Constituinte, foi crucial para a concentração de poderes do Tribunal no sistema jurídico, fortalecendo sobremaneira o Poder Judiciário ante os demais Poderes.

\section{CONSIDERAÇÕES FINAIS: JURISTAS E MINISTROS COMO BENEFICIÁRIOS DA JURISTOCRACIA}

A revisitação de momentos históricos, como a Assembleia Nacional Constituinte, é importante para compreender os mecanismos de manipulação, construção da memória e narrativas de seus desdobramentos. A CRFB conferiu ao STF destacado papel, em contraposição ao enfraquecimento institucional do período ditatorial.

A expansão das suas competências e dos instrumentos de controle de constitucionalidade, o desenho institucional independente e as garantias de seus membros (vitaliciedade e responsabilidade apenas pela via do impeachment, por exemplo) fortalecem o exercício de poder pelo STF, protegido de eventuais ingerências de titulares de outros Poderes. Os meios processuais permitem que as pretensões dos mais diversos setores da sociedade civil sejam encaminhadas ao Tribunal. E, por fim, a adoção de uma carta analítica, permeada de compromissos substantivos, viabiliza a conversão de expectativas políticas em demandas jurídicas. Tem-se aqui a conjunção de fatores que favorecem a relevância do STF no cenário político brasileiro.

Para entendimento destas causas, o estudo da história do processo constituinte, com a análise de documentos, oferece dados importantes. Como lembra Le Goff (2003, p. 422), “os esquecimentos e os silêncios da história são reveladores desses mecanismos de manipulação da memória coletiva”. É importante compreender o direito e suas instituições como fenômeno histórico, como produto das condições políticas e sociais de um certo momento.

A participação de grupos específicos nos acontecimentos decisivos das sociedades é, muitas vezes, manipulada ou pormenorizada pelos grupos dominantes. Neste sentido, resgatar a influência dos próprios ministros do STF no processo constituinte que fortaleceu o Tribunal, criando as condições institucionais para a judicialização da política no Brasil, mostra que o Poder Judiciário 
mobilizou-se para assegurar sua relevância no arranjo político, de sorte que não foi - e não é - apenas objeto deste processo histórico, mas seu sujeito ativo.

A hipótese da autopreservação hegemônica, formulada por Ran Hirschl como explicação para a juristocracia, é confirmada no sistema brasileiro, no que concerne à participação de juristas e juízes na Assembleia Constituinte, por meio dos mecanismos regimentais e também de intenso lobby político, como mostra a historiografia. A despeito das divergências entre acadêmicos e representantes das distintas inclinações ideológicas quanto ao formato, competências e composição da instituição, as preferências dos ministros recaíram sobre a manutenção do desenho então vigente e ampliação de suas competências. A influência dos juristas era esperada numa Constituinte que contou com expressivo percentual de advogados entre seus membros, instaurada sob os influxos da efervescência de teorias jurídicas e da esperança nas potencialidades do projeto constitucional.

Diante do exposto, a contribuição ao debate consiste na revisão de um dos seus mais notáveis elementos - as condições jurídico-institucionais que permitem a atuação do Judiciário em questões controvertidas. Trinta anos após a instauração da Assembleia Nacional Constituinte, sugere-se o resgate das expectativas e do arranjo político-social que conferiu normativamente ao Poder Judiciário inédito relevo entre os Poderes, na tentativa de valorização do entendimento de momentos históricos e de suas consequências para a contemporaneidade.

Se magistrados e juristas são, a despeito das críticas direcionadas à consolidação de uma juristocracia, agentes participantes e beneficiários diretos de contextos de fortalecimento do direito e suas agências, resta saber quais os interesses específicos - no caso brasileiro - que mobilizaram - e mobilizam - as elites econômicas e políticas para a adesão ao protagonismo judicial. O estudo da história desvenda pressupostos, mas deixa em aberto questionamentos sobre as condições atuais e futuras.

\section{REFERENCIAS}

ABRANCHES, Sérgio Henrique H. de. Presidencialismo de coalizão: o dilema institucional brasileiro. Dados: Revista de Ciências Sociais, v. 31, n. 1, p. 5-32, 1988.

ALMEIDA, Frederico Normanha Ribeiro de. A nobreza togada: as elites jurídicas e a política da Justiça no Brasil. 2010. Tese (Doutorado em Ciência Política) - Faculdade de Filosofia, Letras e Ciências Humanas, Universidade de São Paulo, São Paulo, 2010.

ANDRADE, Louise Dantas de. Agenda-setting: análise do comportamento do Supremo Tribunal Federal no controle concreto de constitucionalidade. Recife: Universidade Católica de Pernambuco (Mestrado em Direito), 2015. 
ARTURI, Carlos S. O debate teórico sobre mudança de regime político: o caso brasileiro. Revista de Sociologia e Política, Curitiba, n. 17, p. 11-31, nov. 2001.

BACKES, Ana Luiza; AZEVEDO, Débora Bithiah de; ARAÚJO, José Cordeiro de (Org.). Audiências públicas na Assembleia Nacional Constituinte - a sociedade na tribuna. Brasília: Edições Câmara, 2009.

BRASIL. Assembleia Nacional Constituinte. Parecer Final do Relator. Disponível em: <https://goo.gl/TaO0bP>. Acesso em: 12 out. 2016.

BRASIL. Assembleia Nacional Constituinte. Resolução n 2 de 1987. Dispõe sobre o Regimento Interno da Assembleia Nacional Constituinte. Disponível em: <https://goo.gl/LJswGI>. Acesso em: 20 dez. 2017.

BRASIL. Constituição da República dos Estados Unidos do Brasil, de 24 de fevereiro de 1891. Disponível em: <https://goo.gl/sAFzr>. Acesso em: 3 nov. 2012.

BRASIL. Constituição da República dos Estados Unidos do Brasil, de 16 de julho de 1934. Disponível em: <https://goo.gl/SsgAZ>. Acesso em: 3 nov. 2012.

BRASIL. Constituição da República Federativa do Brasil de 1988. Disponível em: <https://goo.gl/zaRrL>. Acesso em: 3 nov. 2012.

BRASIL. Constituição da República os Estados Unidos do Brasil, de 18 de setembro de 1946. Disponível em: <https://goo.gl/glZTW>. Acesso em: 3 nov. 2012.

BRASIL. Constituição dos Estados Unidos do Brasil, de 10 de novembro de 1937. Disponível em: <https://goo.gl/7CtHjw >. Acesso em: 4 nov. 2012.

BRASIL. Decreto $n^{0}$ 848, de 11 de outubro de 1890. Diário Oficial da União. Rio de Janeiro, 1890. Disponível em: <https://goo.gl/qonBq2>. Acesso em: 15 nov. 2016.

BRASIL. Emenda Constitucional no 7, de 13 de abril de 1977. Incorpora ao texto da Constituição Federal disposições relativas ao Poder Judiciário. Disponível em: <https://goo.gl/v2QkLn>. Acesso em: 11 nov. 2016.

CARVALHO NETO, Ernani Rodrigues de. A ampliação dos legitimados ativos na Constituinte de 1988: revisão judicial e judicialização da política. Revista Brasileira de Estudos Políticos, n. 96, p. 293-325, jul./dez., 2007.

CARVALHO, Ernani Rodrigues de. Revisão abstrata de legislação e judicialização da política no Brasil. São Paulo: USP (Tese de Doutorado), 2005.

CARVALHO, Ernani. Trajetória da revisão de constitucionalidade no desenho institucional brasileiro: tutela, autonomia e judicialização. Sociologias, Porto Alegre, ano 12, n. 23, p. 176-207, jan./abr. 2010. 
CARVALHO, Ernani; BARBOSA, Luis Felipe Andrade; GOMES NETO, José Mário Wanderley. OAB e as prerrogativas atípicas na arena política da revisão judicial. Revista Direito GV, São Paulo, p. 69-98, jan-jun., 2014.

CODATO, Adriano Nervo. Uma história política da transição brasileira: da ditadura militar à democracia. Revista de Sociologia e Política, Curitiba, n. 25, p. 83-106, nov. 2005.

CORRÊA, Oscar Dias. O Supremo Tribunal Federal, corte constitucional do Brasil. Rio de Janeiro: Forense, 1987.

COSTA, Alexandre Araújo; CARVALHO, Alexandre Douglas Zaidan de; FARIAS, Felipe Justino de. Controle de constitucionalidade no Brasil: eficácia das políticas de concentração e seletividade. Revista Direito GV, São Paulo, v. 12, n. 1, p. 155-187, jan./abr. 2016.

CRUZ, Álvaro Ricardo de Souza. Jurisdição constitucional democrática. Belo Horizonte: Del-Rey, 2004.

DELGADO, Tarcisio. A história de um rebelde. Brasília: Fundação Ulysses Guimarães, 2006.

FEREJOHN, John. Judicializing politics, politicizing law. Law and Contemporary Problems, v. 65, n. 3, p. 41-69, 2002.

GOMES, Sandra. O impacto das regras de organização do processo legislativo no comportamento dos parlamentares: um estudo de caso da Assembléia Nacional Constituinte (1987-1988). Dados, Rio de Janeiro, v. 49, n. 1, p. 193-224, 2006.

HIRSCHL, Ran. Towards juristocracy. The origins and consequences of the constitutionalism. Cambridge: Harvard University Press, 2004.

KOERNER, Andrei. Judiciário e cidadania na Constituição da República Brasileira. São Paulo: Hucitec/Departamento de Ciência Política, USP, 1998.

KOERNER, Andrei; FREITAS, Lígia Barros de. O Supremo na constituinte e a constituinte no Supremo. Lua Nova, São Paulo, n. 88, p. 141-184, 2013.

LAMOUNIER, Bolívar (org.). De Geisel a Collor: o balanço da transição. São Paulo: Idesp/Sumaré, 1990.

LE GOFF, Jacques. História e memória. 5. ed. São Paulo: Unicamp, 2003.

LIMA, Flávia Santiago. Dirigismo e comunitarismo no processo constituinte brasileiro: considerações sobre a opção pelo Estado Democrático e Social de Direito. Revista da AGU, v. 8, n. 21, p. 143-162, jul./set., 2009.

LIMA, Flávia Santiago. Jurisdição constitucional e política: ativismo e autocontenção no STF. Curitiba: Juruá, 2014. 
LOUBACK, Joyce. Os conceitos de igualdade, cidadania e democracia nos discursos do campo popular ao longo da Assembleia Constituinte de 1987-1988. Rio de Janeiro: UERJ (Tese de Doutorado), 2016.

PILATTI, Adriano. A Constituinte de 1987-1988 - progressistas, conservadores, ordem econômica e regras do jogo. Rio de Janeiro: PUC, 2008.

PRZEWORSKI, Adam. The Games of Transition. In: MAINWARING, S., O’DONNELL, G. \& VALENZUELA, A. Issues in Democratic Consolidation: The New South American Democracies in Comparative Perspective. Notre Dame: University of Notre Dame Press, 1992.

RECONDO, Felipe. Tanques e togas - o STF e a ditadura militar. São Paulo: Companhia das Letras, 2018.

ROCHA, Antônio Sérgio. Genealogia da Constituinte: do autoritarismo à democratização. Revista Lua Nova, n. 88, São Paulo, p. 29-87, 2013.

SADEK, Maria Tereza. A organização do Poder Judiciário no Brasil. SADEK, Maria Tereza (Org.). Uma introdução ao estudo da Justiça. São Paulo: Sumaré, 1995, p. 9-16.

SANTOS, Boaventura de Sousa. Direito e democracia: a reforma global da justiça. In: PUREZA, José Manuel, FERREIRA, António Casimiro (Org.), A teia global. Movimentos sociais e instituições. Porto: Afrontamento, 2001, p. 125-177.

SOUZA, Márcia Teixeira de. O processo decisório na Constituição de 1988: práticas institucionais. Revista Lua Nova, n. 58, São Paulo, p. 37- 60, 2003.

TAVARES FILHO, Newton. Subcomissão do Poder Judiciário e do Ministério Público. In: BACKES, Ana Luiza; AZEVEDO, Débora Bithiah de; ARAÚJO, José Cordeiro de (Org.). Audiências públicas na Assembleia Nacional Constituinte - a sociedade na tribuna. Brasília: Edições Câmara, 2009, p. 219-238.

TAYLOR, Matthew M. O Judiciário e as políticas públicas no Brasil. Dados - Revista de Ciências Sociais, Rio de Janeiro, v. 50, n. 2, p. 229-257, 2007.

VIANNA, Luiz Werneck; BURGOS, Marcelo Baumann; SALLES, Paula Martins. Dezessete anos de judicialização da política. Tempo Social (Revista de Sociologia da USP), v. 19, n. 2, p. 39-85, 2007.

VIEIRA, Oscar Vilhena. Supremo Tribunal Federal. Jurisprudência política. São Paulo: Malheiros, 2002.

VIEIRA, Oscar Vilhena. Supremocracia. Revista Direito GV, v. 4, p. 441-459, 2008.

Flávia Danielle Santiago Lima Professora do PPGD-UFPE, da Universidade de Pernambuco (UPE) e da Universidade Católica de Pernambuco (Unicap). Pesquisadora visitante na Universitat de València. Advogada da União.E-mail: flavia-santiago@uol.com.br 